\title{
Contagion, Policy, Class, Gender, and Mid-Twentieth-Century Lancashire Working-Class Health Culture
}

\author{
Lucinda M. Beier
}

\section{Introduction}

$\mathrm{F}$ rom earliest times, governments have been concerned about the threat posed by epidemics and have embraced policies and regulations intended to prevent or limit the impact of diseases identified as contagious. ${ }^{1}$ However, the public health initiatives of nineteenth- and early twentieth-century England were more ambitious, inclusive, and sustained than any previous public attempts to control disease. ${ }^{2}$ The sanitation reforms and preventive health services implemented from the 1840s onward had an enormous impact on the quality and duration of life experienced by English people. Indeed, in his challenge to the McKeown thesis, Simon Szreter argues, 'The public health movement working through local government, rather than nutritional improvements through rising living standards, should be seen as the true moving force behind the decline of mortality in this period.'

1 See, for example, Dorothy Porter, Health, Civilization and the State: A History of Public Health from Ancient to Modern Times (London and New York, 1999) and George Rosen, The History of Public Health (New York, 1958).

2 See, for example, Anthony S. Wohl, Endangered Lives: Public Health in Victorian Britain (Cambridge, Mass., 1983); Christopher Hamlin, Public Health and Social Justice in the Age of Chadwick: Britain, 1800-1854, (Cambridge, 1998); Ann Hardy, The Epidemic Streets: Infectious Disease and the Rise of Preventive Medicine, 1856-1900 (Oxford, 1993); Urban Disease and Mortality in Nineteenth-Century England, eds. Robert Woods and John Woodward (New York, 1984).

3 Simon Szreter, 'The Importance of Social Intervention in Britain's Mortality Decline c. 1850-1914: A Re-interpretation of the Role of Public Health', Social History of Medicine, 1:1 (1988), 1 refers to T. McKeown's The Modern Rise of Population (London, 1976), which chal- 
Yet, public health policies were also intrusive, interfering with individual decision-making and traditional health cultures in the name of the public good. In his review of the state's changing role in disease prevention in his Eleventh Annual Report (1868), John Simon, chief administrator of the Medical Department of the Privy Council, recognised the state's intrusion into relationships previously outside its purview:

[The state] has interfered between parent and child, not only in imposing limitation on industrial uses of children, but also to the extent of requiring that children should not be left unvaccinated. It has interfered between employer and employed, to the extent of insisting, in the interest of the latter, that certain sanitary claims shall be fulfilled in all places of industrial occupation. It has interfered between vendor and purchaser; has put restrictions on the sale and purchase of poisons, has prohibited in certain cases certain commercial supplies of water, and has made it a public offence to sell adulterated food or drink or medicine, or to offer for sale any meat unfit for human food. Its care for the treatment of disease has not been unconditionally limited to treat at the public expense such sickness as may accompany destitution: it has provided that in any sort of epidemic emergency organized medical assistance, not particularly for paupers, may be required of local authorities; and in the same spirit it requires that vaccination at the public cost shall be given gratuitously to every claimant.

Research on the history of public health in nineteenth- and twentieth-century England has focused largely on political, institutional, and professional issues; the impact of public health policies on the individuals, families, communities, and cultures upon which they were enforced has received comparatively little scholarly attention. ${ }^{5}$ This is particularly true regarding working-class communities - the primary focus of public health concerns and policies, since statisticians, physicians, moral reformers, and policy-makers observed a strong relationship between infectious disease and poverty. ${ }^{6}$ This paper will contribute to the scholarship by exploring the impact of both contagious diseases and public health policies on working-

lenged then current orthodoxy that the rise of modern scientific medicine had brought about the mortality decline, arguing instead that improved diet solely accounted for that decline.

4 Quoted in Roy Porter, The Greatest Benefit to Mankind (London, 1997), 414-15.

5 There are, of course, exceptions to this generalisation. See, for example, F. B. Smith, The People's Health 1830-1910 (New York, 1979) and Nadja Durbach, " "They Might as well Brand Us": Working-Class Resistance to Compulsory Vaccination in Victorian England', Social History of Medicine, 13:1 (2000), 45-62. Excellent recent studies of US experience include Judith Walzer Leavitt, Typhoid Mary: Captive to the Public's Health (Boston, 1996) and Nancy Tomes, The Gospel of Germs: Men, Women, and the Microbe in American Life (Cambridge, Mass., 1998).

6 See, for example, Anthony S. Wohl, Endangered Lives, Chapter 3, 43-79. Urbanising Britain: Essays on Class and Community in the Nineteenth-Century, eds. Gerry Kearns and Charles W. J. Withers (Cambridge, 1991). 
class experience three Lancashire communities during the first half of the twentiethcentury.

The paper is largely based on information resulting from more than 200 semistructured life history interviews conducted with residents of Barrow, Lancaster, and Preston by Dr. Elizabeth Roberts and myself during the 1970s and 1980s.' (See the Appendix for information about interviewees and interview questions.) Covering the first half of the twentieth-century, these interviews offer perspectives on working-class health culture and behaviour that are not available from other sources. For example, while annual returns of the Medical Officer of Health of each community supply data on the incidence and management of specific contagious diseases and occasionally offer descriptions or analyses of working-class experience, these documents are written from a point of view that is invariably different from that of local working-class residents. ${ }^{8}$ Equally, the Friendly Society Records, mined so effectively by James C. Riley and others, are particularly revealing about the health, illness, and care of adult male workers, leaving in obscurity the experience of most women and children, who were excluded from coverage. ${ }^{9}$ Evidence from the Lancashire oral history interviews, thus, balances and enhances the perspectives offered by documentary evidence. It also adds to the growing literature based on oral sources about popular experience of ill health and medical care in Britain. ${ }^{10}$

7 Elizabeth Roberts interviewed approximately 160 people in the course of projects funded by the Social Science Research Council in 1974-6 and 1978-81. With support from the Economic and Social Research Council, Dr. Roberts and I interviewed an additional 98 respondents between 1987 and 1989. Interview transcripts are housed in the archive of the Centre for North-West Regional Studies at Lancaster University (Great Britain).

8 For example, Jane Lewis in her What Price Community Medicine: The Philosophy, Practice and Politics of Public Health Since 1919 (Brighton, Sussex, 1986) criticises the Medical Officers of Health $(\mathrm{MOH})$ of the 1930s for their 'optimistic' annual reports designed to reassure the public that national health was being looked after. Thus, both health needs, on the one hand, and traditional working-class self-help in dealing with matters of health and illness, on the other, do not find their way into MOH returns. (Lewis, 30). Reports of the Barrow, Lancaster, and Preston MO'sH tend to blame working-class families for their own health problems.

9 See, for example, James C. Riley, Sick, Not Dead: The Health of British Workingmen During the Mortality Decline (Baltimore, 1997) and David G. Green, Working-Class Patients and the Medical Establishment: Self-Help in Britain from the Mid-nineteenth-Century to 1948 (New York, 1985).

10 For a discussion of sources see Paul Thompson, 'Oral History and the History of Medicine: A Review', Social History of Medicine, 4:2 (1991), 371-383. For twentieth-century working-class experience, see Pam Schweitzer and Joyce Holliday, Can We Afford the Doctor? (London 1985); and Elizabeth Roberts, 'Oral History Investigations of Disease and its Management by the Lancashire Working Class 1890-1939', in Health, Disease and Medicine in Lancashire 1750-1950, ed. John Pickstone, Occasional Publications No. 2, Department of History, Science and Technology, UMIST (Manchester, 1980), 33-51. Jocelyn Cornwell's HardEarned Lives: Accounts of Health and Illness from East London (London, 1984) explores 1980s working-class London health culture, but does not provide an historical perspective. Regarding 
This paper makes the following arguments:

1. Policy-driven local management of contagious disease was an important vehicle for the transition of power from informal, 'amateur', home-based, female, working-class authority in matters of health and medicine to formal, 'expert', institutional, male, middle class authority. It is not my intention to argue that working-class communities would have been better off without the benefits of public health and medical intervention. However, it is undeniable that intrusions of the health bureaucracy into working-class life undermined traditional family and neighbourhood ways of managing ill-health and, by extension, the power, status, and confidence of working-class women. ${ }^{11}$

2. This transition was slow in coming because it was resisted by the people in working-class communities with the most knowledge and influence regarding health matters - mothers, grannies, and 'handywomen' (informal neighbourhood health authorities). Resistance was understandable because, as the evidence cited below indicates, official health care was often intrusive, frightening, and expensive, disrupting family life and violating traditional health care patterns sanctioned by working-class health culture.

3. Finally, however, the transition was effective because of a combination of local delivery of information and services (in elementary schools and neighbourhood clinics), the power of the public health bureaucracy to enforce its decisions, and, ultimately, the establishment of the NHS and the introduction of antibiotics.

twentieth-century experience of midwives and their working-class patients, see The Midwife's Tale: An Oral History from Handywoman to Professional Midwife, eds. Nicky Leap and Billie Hunter (London, 1993).

11 Elizabeth Roberts, Women and Families: An Oral History, 1940-1970 (Oxford, 1995), 238. For additional information about the transition from informal, neighbourhood management of ill-health to dependence on formal health care providers, see Lucinda McCray Beier, "I used to take her to the doctor's and get the proper thing": Twentieth-Century Health Care Choices in Lancashire Working-Class Communities', in Splendidly Victorian, eds. M. Shirley and T. Larson (Aldershot, 2001). 


\section{Contagious Diseases}

By the end of the nineteenth-century, mortality from most epidemic and endemic contagious diseases had already begun the rapid decline that continued in the twentieth-century. ${ }^{12}$ Nonetheless, with the popularisation of the germ theory among the upper and middle classes, public concern about transmission of diseases among individuals grew, as did policy-driven activities directed at prevention, treatment, isolation, and education. The new local health bureaucracies increasingly enforced regulations including compulsory vaccination; notification of cases of a growing number of contagious diseases; isolation in either home quarantine or fever hospitals; fumigation of homes; inspection of school children; and other measures intended to protect the general population from the sick among them. ${ }^{13}$ Furthermore, through the agency of state education and the School Medical Service, established in 1907, elite consensus about cause, prevention, and treatment of disease was introduced to a new audience - working-class children. ${ }^{14}$ These public health activities both elicited resistance and, in the long run, produced change in workingclass health culture.

Oral history respondents remembered the contagious diseases experienced within their childhood and adult households, making a clear distinction between 'ordinary childhood diseases', including measles, chicken pox, mumps, and whooping cough, and more serious life-threatening ailments such as diphtheria, scarlet fever, meningitis, polio, and tuberculosis. Measles was the illness most often mentioned, followed by chicken pox and mumps. Respondents displayed a high degree of indifference towards 'ordinary childhood diseases', despite complications including deafness and asthma after measles and a death from whooping cough. ${ }^{15}$ Indeed,

12 See, for example, Riley, Sick, Not Dead, Hardy, Epidemic Streets, and Szreter, 'The Importance of Social Intervention'.

13 See, for example, Porter, Health, Civilization and the State, 118 ff.; Hardy, Epidemic Streets, 267-280; Bernard Harris, The Health of the Schoolchild: A History of the School Medical Service in England and Wales (Buckingham, 1995); and Jane Lewis, What Price Community Medicine: The Philosophy, Practice and Politics of Public Health since 1919 (Brighton, 1986).

14 Harris, The Health of the Schoolchild; John Woodward, 'The School Medical Officer Before the School Medical Service: England and Wales, 1850-1908', in Coping with Sickness: Historical Aspects of Health Care in a European Perspective, eds. John Woodward and Robert Jütte (Sheffield, 1995), 121-146.

15 Interviewees were promised anonymity; thus, names used in this narrative are fictitious. References to interview transcripts, housed by the Center for North-West Regional Studies, Lancaster University (Great Britain) are given by the respondent's code number and transcript page number. Barrow respondents are indicated by the suffix 'B', Lancaster respondents by the suffix 'L', and Preston respondents by the suffix 'P'. For representative comments regarding "ordinary childhood diseases", see Mr. G3L p. 46, Mrs. C8L, p. 6, and Mrs. P1P, pp. 14-15. The indifference toward many 'childhood' illnesses displayed by these Lancashire 
families were so resigned to the inevitability of these diseases that children were deliberately exposed to active cases in order to 'get it over with', despite official recommendations to isolate sufferers. Passive response to 'ordinary childhood diseases' spanned generations. Mr. Kellett, born in Preston in 1930, was not unusual in remembering that 'If you used to get mumps or anything like that we used to be chucked together in one bed. We slept in one bed anyway, so we had to be near certain of all getting it whatever was going at the time.' Mr. Farrell, born in Lancaster in 1917, joked that, 'The only time I kissed our Roger [his brother] was to get measles off him'. ${ }^{16}$ Respondents were much more alarmed by diphtheria, tuberculosis, and scarlet fever, which were not only considered more dangerous, but because of public health regulations disrupted traditional management of illness, withdrew the sufferer from ordinary life for a considerable period of time, inconvenienced family members, and cost money.

In the first half of the twentieth-century, virtually all illnesses - particularly those suffered by children - were dealt with at home by laywomen. Although a range of formal health services were available, mothers, grandmothers, and neighbourhood health authorities diagnosed, provided advice, prescribed and administered medicine (often home-made), attended births and deaths, and nursed the sick. ${ }^{17}$ Women also visited ailing neighbours and helped with food preparation, childcare, shopping, and other housework. ${ }^{18}$ Making health decisions and managing illness was an expected part of a woman's role, adding to both her responsibilities and her status. Mrs. Wallington, born in 1923, spoke for many when she remembered, 'If you had chicken pox, your mum knew what to do and what you had, and that was it'. ${ }^{19}$ What mum was likely to do generally involved keeping the patient warm in bed, surrounded by family members and neighbours, and using a range of home-made or patent remedies to deal with symptoms. These approaches were different from

respondents was not unusual. Ann Hardy discusses similar indifference observed among workingclass London residents in the late nineteenth-century in Epidemic Streets, 270-71.

16 Mr. K2P, p. 83, Mr. F2L, p. 79.

17 Leap and Hunter's The Midwife's Tale provides an excellent discussion of the work of 'handywomen' - working-class neighbourhood health authorities - who remained active until the mid-twentieth-century. My own research on seventeenth-century English health culture, discussed in Sufferers and Healers: The Experience of Illness in Seventeenth-Century England (London, 1987) suggests that twentieth-century working-class health culture retained the tradition of women serving as health authorities and care-givers within their households and neighbourhoods. I discuss oral evidence for this survival in my paper, "II used to take her to the doctor's and get the proper thing”: Twentieth-Century Health Care Choices in Lancashire Working-Class Communities'.

18 Elizabeth Roberts, A Woman's Place: An Oral History of Working-Class Women 18901940 (Oxford, 1986), 169-201; Elizabeth Roberts, Women and Families, 201-02.

19 Mrs. W4L, p. 33. See also, for example, Mr. B2B, pp. 38-39, Mrs. P6B, p. 117, Mrs. F1L, p. 49, Mrs. H5L, p. 58, Mrs. T2L, p. 77. 
those used by physicians and the public health establishment, which emphasised isolation and avoidance of traditional remedies.

Although working-class families did consult physicians, it is arguable that men were more likely than women or children to do so because their care was more often paid for by Friendly Society coverage or, after 1911, the 'Lloyd George' National Insurance program. ${ }^{20}$ Thus, in part, working-class women avoided using official medical care for themselves or their children because of its cost. Mrs. Allen, born in 1932, remembered, 'If she [mother] thought I was really ill, she would send for the doctor. She would try and probably cure me first herself, because then they'd to pay. And then, if it didn't work, she would send for the doctor'. ${ }^{21}$ Some families were involved in pre-paid hospital or medical schemes; others paid off doctors' bills at the rate of a penny or two collected weekly by the doctor's 'man' on Friday (pay-day) evening.

An infectious disease often took the choice of whether or not to use official medicine out of the family's hands, since the law required certain illnesses to be reported and sufferers to be treated in isolation hospitals. ${ }^{22}$ Mrs. Aubrey, born in 1907 , spent four months in an isolation hospital being treated for scarlet fever when she was three years old. Although her hospital treatment was free, doctor's visits and medication were not. She said, 'I think m'mother paid that doctor's bill for years.... They used to have to pay it weekly. M'mother said that they just hadn't any money to pay it, they used to have to take so much every week to pay him off. ${ }^{23}$

Families resisted having children confined in isolation hospitals for other reasons more often cited than expense. Any hospitalisation was upsetting because it represented a departure from the usual way of handling ill health. Mr. Goodwin, born in 1945, didn't like his hospitalisation for a tonsillectomy as a child because 'We was always home with the family, and to be away from the family was something strange. ${ }^{24}$ However, hospitals - and particularly isolation hospitals - were also

20 In Riley, Sick, Not Dead, the author maintains that 'In Britain workingmen began regularly to consult formal medical practitioners between the late eighteenth and the mid-nineteenth centuries' (47) and that 'The friendly societies brought working-class males as a group into contact with formal medicine' (51). He recognises that 'although many children and women belonged, friendly societies served chiefly adult males' (30). See also Helen Jones, Health and Society in Twentieth-Century Britain, (London and New York, 1994), 20-27.

21 Mrs. A4L, p. 75. See also, for example, Mr. F1L, p. 29, Mrs. F1L, p. 47, Mr. H7L, p. 65.

22 Fever hospitals were built in England beginning in the late eighteenth-century. However, there was a 'new burst of building isolation hospitals' in the 1880s (Smith, People's Health, 241) associated with the same movement that stimulated passage of the Notification of Infectious Diseases Act of 1889. Barrow, Lancaster, and Preston each had isolation hospitals that were used during the first half of the twentieth-century for cases of diphtheria, scarlet fever, and typhoid. There were also sanitoria used exclusively by tuberculosis patients.

23 Mrs. A2L, p. 214.

24 Mr. G6P, p. 62. See also Mr. N2., p. 60. 
regarded as dangerous. Mrs. Aubrey lost an eye due to an infection she picked up while hospitalised in 1910 for scarlet fever. When her own daughter had scarlet fever, Mrs Aubrey resisted having her hospitalised. ${ }^{25}$ Mrs. Pierce, born in 1899, had a four-year-old son suffering from measles and year-old twins, who had whooping cough, removed from her home by 'the Welfare' and taken to the isolation hospital in Preston where one of the twins died. When her husband came home from work, 'He said that I had no business letting them [take the boys]. You can't go against them people, can you. I were demented, I didn't know what I were doing'.

Even when hospitalisation did not have disastrous results, it separated children from their families for a long time and imposed unfamiliar care routines. $\mathrm{Mr}$. Goodwin, born in 1903, was in the Preston isolation hospital for six weeks in 1914:

When you went in, you could have had scarlet fever for a week. It made no difference to them, they treated you the same. You went for three days and you were only on slops and they kept you laid down. They gradually built you up, but all the time you were in that hospital, you were hungry. . . Parents weren't allowed in. Later on they could come and look through the window. ${ }^{26}$

Mr. Hunter, born in 1928, spent three months in hospital with diphtheria in 1941. ${ }^{27}$ People suffering from tuberculosis were confined in hospital for a much longer period of time - years, rather than months. Treatment was unpleasant, invariably including protracted exposure to the cold and often involving surgery. ${ }^{28}$

Hospitalisation interrupted family relationships and removed authority, control, and knowledge of what was happening to the sufferer from parents. It was terrifying. Mr. Simpkins, born in 1932, reflected general fear of the isolation hospital:

The things that stand out in my memory are the illnesses that were taking place at that time, because I can remember we used to dread seeing the ... blue ambulance come on the [Lancaster Council housing] estate. Because diphtheria was widespread and we used to have a nasty little habit of spitting into the gutter and saying, 'no fever in our house.' You know... People died from diphtheria in those days, you know, and the isolation hospital... You see, and they were not going to go in that blue ambulance, no way, you know, you was never going to come back. ${ }^{29}$

Home quarantine also interrupted family and community life. In addition, it imposed on mothers new, officially sanctioned treatment routines involving a lot of extra work. However, families preferred quarantine to hospitalisation. Mr. Sharples,

25 Mrs. A2L, p. 213.

26 Mr. G1P, p. 12. See also Mr. M13B, p. 56; Mr. R3B, p. 51; Mr. F1L, p. 27; Mr. H3P, pp. 10-12.

27 Mr. H3P, pp. 10-12.

28 Mrs. J1B, p. 4; Mr. W7B, p. 47; Mr. M1L, p. 9; Mr. W7P, p. 40.

29 Mr. S7L, pp. 8, 77. 
born in 1915, described his mother's battle to keep him at home when he contracted scarlet fever:

It was unheard of for anything other than that you went to an isolation hospital, but my mother managed to prevail upon the doctor and the health authority that because I was the only one, she was prepared to take extreme precautions with regard to infection and I was immured in the bedroom for a couple of months and no one was allowed in the room except my mother. I remember the blankets and things soaked in disinfectant, hanging outside the door. $^{30}$

Mrs. Adderley, born in 1932, was also an only child who was quarantined for two months with scarlet fever. She remembered that children were quarantined for 'chicken pox, measles, and everything' and that a 'chap came around' to enforce the quarantine. ${ }^{31}$ Mrs. Peel, born in 1921, also remembered home quarantine and that her father, a postman, had to stay at home if any of his children had an infectious illness. $^{32}$

In additional to reporting cases of specific 'notifiable' diseases and isolating sufferers in hospitals or home quarantine, public health authorities were also responsible for fumigating ('stoving') infected premises after the sufferer had died or recovered. Mr. Goodwin remembered how this was managed in Preston in 1914:

They had the Town Doctor and he used to come to the house and they would say as we had had scarlet fever and this house had to be stoved. They would ask where the child was and they would say in such a bedroom. I remember it was a three-bedroomed house and they came and they did all three bedrooms. They left the rest of the house. It was like sulphur in a round tin and they put one in each bedroom and they lit it. They sealed all the bedroom doors and windows up with sticky brown paper. They would do that in the morning and then at night they would come and take this brown paper off and open the doors and windows. ${ }^{33}$

Respondents also remembered houses being stoved for insect infestations. ${ }^{34}$

Public health authorities were also responsible for administering immunisations, beginning with smallpox vaccination (compulsory after 1853) and including immunisation against diphtheria, tetanus, whooping cough, tuberculosis, and polio by the mid-twentieth-century. Although many respondents remembered having 'everything', the experience of others revealed widespread working-class resistance

30 Mr. S4P, p. 4.

31 Mrs. A4L, p. 77.

32 Mrs. P6B, pp. 13, 118.

33 Mr. G1P, p. 11. See also, for example, Mr. F1L, p. 28 and Mr. M10L, p. 57.

34 Mrs. N3L, p. 32; Mrs. B11P, p. 19. 
to vaccination and immunisation. ${ }^{35}$ Mrs. Swallow, born in 1948 , said that her mother did not believe in any type of immunisation because 'She thought that they were putting something in your body that shouldn't be there anyway' ${ }^{36}$ Mrs. Canter, born in 1942, thought that immunisations 'injected the germ' into children. ${ }^{37}$ Mrs. Sykes, born in 1927, said her mother thought vaccination was a 'messy thing', while Mrs. Ruthven's (born 1936) father disapproved of vaccination on 'conscientious grounds' and Mr. Thornbarrow's (born 1949) parents obtained a doctor's signature to 'get out of it [vaccination]. ${ }^{38}$ Nonetheless, many respondents remembered immunisations being done without parental permission, either at school, in the army, or by local health authorities during an epidemic. ${ }^{39}$

After establishment of the School Medical Service in 1907, schools became agents for inspection of children, disease prevention, and treatment of some health problems. Most respondents remembered being inspected for head lice at school. Mrs. Needham, born in 1919, remembered that 'every week you had a nurse come'. If lice or nits were found, the child would be 'sent to the clinic and kept away from school.' This shamed the child, 'Because it wasn't so nice if you got pulled up in front of all the other kids with nits. Because they took you to one side if you had got it, you see. . . And then it used to be, "Oh I'm not sitting next to her, she's nits", you know. So you didn't want them, did you? ${ }^{\text {40 }}$

Many respondents remembered being given 'emulsion' at school to prevent illness. Mr. Newberry, born in 1931, said,
Well, we were given emulsion at school and we were given cod-liver oil cap- sules at school, but again this was during the war where... vitamins were in short supply anyway. And we didn't decide to have these things, it was decided for us... And we were all told we had got to bring our own spoon to school... And in order to identify a particular spoon it was suggested that we wrap a piece of coloured wool round it or raffia, so that you knew whose spoon was whose. ${ }^{41}$

Several respondents were sent to open air schools to 'build them up', either because they had been ill, or to prevent illness. ${ }^{42}$ Most respondents also received treatments

35 See, for example, Nadja Durbach, “ "They Might as well Brand Us.” Working-Class Resistance to Compulsory Vaccination in Victorian England', 45-62.

36 Mrs. S6L, p. 24.

37 Mrs. C8L, p. 18.

38 Mrs. S3B, p. 74, Mr. and Mrs. T4B, p. 75.

39 Mr. F1L, p. 32, Mrs. F1L, p. 62, Mr. N2L, p. 54, Mrs. S6L, p. 24.

40 Mrs. N3L, pp. 31-32.

41 Mr. N2L, pp. 52-3. See, also, for example, Mrs. A4L, p. 74 and Mr. N3L, pp. 128, $133-4$.

42 See, for example, Mr. S4B, p. 65, Mr. BllP, pp. 4, 21. 
from school dentists, who were often detested. ${ }^{43}$ Schools made recommendations regarding diet and bed times. ${ }^{44}$ Thus, schools were an important bridge between 'modern', 'scientific' medicine and working-class health culture. At school, children came into regular contact with health care professionals whose attention they were powerless to resist. They received treatment and information from authorities very different from mother, granny, and the neighbourhood handywoman. It is arguable that this experience had a long-term impact on working-class health culture, making adherence to traditional forms of prevention and treatment increasingly 'old-fashioned'. ${ }^{45}$

Child health clinics also contributed to increasing working-class acceptance of professional medicine and official health culture. Some respondents indicated distrust of clinics, one referring to them as a 'breeding ground for gossip' and another remembering that she stopped going to the clinic when a staff member told her her daughter would be bow-legged because of wearing nappies. ${ }^{46}$ However, many took advantage of the cheap or free supplies offered by clinics and, particularly among younger respondents, took advice from clinic staff about health problems. ${ }^{47}$

Public health authorities wielded a great deal of power in working-class communities. This power was often exercised by men and women of a higher social class than the people affected by it. As in the case of the 'nit nurse' visiting elementary school classrooms, the unintended effects were at some times irritation and at other times shame. For example, Mrs. Jenkins, born in 1932, remembered that her mother-in-law would not let the health visitor into the house, calling her 'an interfering busybody. ${ }^{48} \mathrm{Mr}$. Boyle, born in 1936, recalled his experience with clinic services as a child:

Now, on Harrison Hill, they classed theirselves as different families than what we were. We were scum to them. I'll give you an instance. Me, my brothers and sisters all got what they called at the time, impetigo, which is scabies. So you had to go to this place which is called Atkinson Street and it must have been a public house at one time and they had changed it, the Health must

43 Respondents complained of school dentists being heavy-handed and callous, preferring extraction to other treatments, using slow (foot-operated) drills without anaesthetic, and dealing with groups of school children in an assembly-line fashion. See, for example, Mrs. B2B, p. 54, Mrs. J1B, p. 67, Mr. M12B, p. 46, Mr. P5B, p. 49, Mrs. P5B, p. 43, Mr. R3B, p. 61, Mrs. S4B, p. 65, Mrs. T4B, p. 75, Mr. W7B, p. 44, Mr. G3L, pp. 31 and 48, Mrs. H5L, pp. 6162, Mr. N2L, pp. 63-66, Mrs. L3P, pp. 120-149.

44 Mrs. B11P, p. 30

45 See, for example, Lucinda McCray Beier, "II used to take her to the doctor's and get the proper thing": Twentieth-Century Health Care Choices in Lancashire Working-Class Communities' and Elizabeth Roberts, Women and Families, 145-150.

46 Mrs. C8L, p. 17; Mrs. O1B, p. 41.

47 Mrs. B2B, p. 50, 53, Mrs. L5B, p. 44, Mr. W4B, p. 22, Mrs. W4L, p. 38.

48 Mrs. J1B, p. 64. 
have changed it. . . And you went there and there were big tin baths and you got in them baths of hot water, and this bloke used to come. . . and scrub these scabs. . . until he made them bleed. Then you got out of the bath and he filled you with this ointment. He had a name for it, it were thick yellow ointment. And then you could put your clothes back on, which you had a woollen vest and one thing and another, and then my Mam would walk us back down the street, and then you would see on the other side were these kids. . 'Don't go up near [Boyles's], they've all got scabies, keep away from them, they've impetigo.' And it went on from that, you see. And that was just around the corner from me. ${ }^{49}$

The Medical Officer of Health (MOH), the general practitioner, the consultant, the health visitor, the licensed midwife - these state-sanctioned agents of official medicine were sometimes avoided by working-class families because of perceived class differences. ${ }^{50}$ Women, traditional working-class health authorities, were at a particular disadvantage when dealing with $\mathrm{MO}$ 's $\mathrm{H}$, physicians, and consultants, most of whom were middle-class males. And once in the hands of the health care system, working-class people were often unable to make decisions or participate in care. Mrs. Fleming, discussing her daughter's hospitalisation for osteomyelitis in the early 1950s, said that parents had very little say in the treatment of their sick children; 'Consultants were like gods..

\section{Conclusions}

By the mid-twentieth-century, several generations of working-class people had received health information and care through schools, clinics, and hospitals. If not embraced with huge enthusiasm, these experiences had at least become part of the normal, expected fabric of life, raising awareness of official health culture and familiarity with professional medicine. These experiences had also gone a long way toward rendering the use of professional medicine 'modern' and dependence on advice and care from lay, working-class women 'old-fashioned'. ${ }^{22}$ This change was enormously advanced, however, by the advent of the NHS in 1948, which eliminated the cost factor, and to some extent the class barrier, in working-class utilisation of professional health care. Mr. Boswell, born in 1920, remembered:

49 Mrs. B11P, p. 17.

50 See, for example, Mrs. J1B, p. 64, Mr. G3L, p. 48, Mr. N2L, p. 53; Elizabeth Roberts, A Woman's Place, 107; Elizabeth Roberts, Women and Families, 148.

51 Mrs. F1L, pp. 116-117.

52 See, for example, Mr. L3B, p. 47, Mr.. R3B, pp. 56-7, Mr. Y1P, p. 51. 
People wanted their teeth out... and wanted a set of dentures, they just could not afford to buy them, so they had aching teeth... Or somebody was ill, send for the doctor, you would get a bill. So they would go down to the chemist and make a bottle up or something like that, you know, and of course the result was that people snuffed it. They had diseases that could have been cured, but they went on too far, so the population was beset with illnesses... And they could not afford to get them treated, so it was the best thing since wearing boots when that [the NHS] came on. ${ }^{53}$

When asked whether there was 'any difference in the way you handled your own children's minor illnesses to the way your mum handled you', Mrs. Burrell, born in 1931, said 'Oh well, yes, I think; we always called a doctor in. I mean, it was National Health Service, so you didn't think twice about calling a doctor in. You didn't have to pay, so. ${ }^{54}$

Another important factor in encourage working-class use of professional medicine was the introduction of antibiotics to the civilian population after World War II. At the same time as demonstrably effective drugs countered home-made poultices and over-the-counter nostrums, the threat of the isolation hospital and the nuisance of home quarantine vanished. According to Dr. Ackerman, a general practitioner who began practising in Lancaster in 1948,

The things that previously had perhaps been put into isolation hospitals, like scarlet fever, sometimes they were still admitted and you swabbed their throat and after penicillin for forty-eight hours and they were negative, you used to get rid of them. Until it became a thing you just didn't put into isolation hospital. Measles, whooping cough, you still had youngsters with measles and whooping cough, but you wouldn't keep them very long. So the isolation in respect of what you call the minor infectious things were out. ${ }^{55}$

Physicians were gatekeepers for the antibiotics that promised a speedy miraculous cure of the contagious illnesses that in the past had hovered over working-class households and communities. Mrs. Owen's (born in 1916) only daughter was born in 1940. While continuing her close relationship with her mother, who lived nearby, Mrs. Owen transferred her reliance in medical matters to her GP. She said, 'If something happened to her [daughter], I used to take her to the doctor's and get the proper thing.' She tolerated her mother's home remedies, allowing:

Mum to goose grease her if she had a bad chest. I used to say, 'That child's got a bad chest,' and out would come the jar of goose grease. An earthenware jar with a piece of brown paper with a rubber ring round, and she would come

53 Mr. B4B, p. 30.

54 Mrs. B2B, p. 53.

55 Dr. A5L, p. 9. 
down and rub her back and front. In the end, I took her [daughter] to the doctor, and he gave me some antibiotics, and it cleared up in no time. ${ }^{56}$

Thus, while even the youngest generation of respondents remembered the use of some traditional home and patent remedies, most also indicated growing reliance on formally-trained medical experts and decreasing recourse to informal health authorities. In the second half of the twentieth-century, the working class woman's role was increasingly confined to the decision about when to consult the doctor and the obligation to carry out his instructions.

56 Mrs. O1B, p. 58. 


\section{Appendix}

\section{Interviewees}

Between 1987 and 1989, Elizabeth Roberts and I interviewed 98 residents of Barrow, Lancaster, and Preston, dividing interviewing responsibilities approximately equally. A deliberate effort was made to balance age, sex, and community of interviewees.

Life History Interviews

\begin{tabular}{cccc}
\hline Date of Birth & Barrow & $\begin{array}{c}\text { Town } \\
\text { Lancaster }\end{array}$ & Preston \\
\hline $1910-1919$ & 2 men & 1 man & - \\
& 2 women & 1 woman & 1 woman \\
$1920-1929$ & 5 men & 6 men & 4 men \\
& 4 women & 5 women & 4 women \\
$1930-1939$ & 6 men & 5 men & 4 men \\
& 6 women & 6 women & 6 women \\
$1940-1949$ & 4 men & 4 men & 6 men \\
& 4 women & 7 women & 4 women \\
1950-1959 & - & - & 1 woman \\
& 17 men & 16 men & 14 men \\
Totals & 16 women & 19 women & 16 women \\
\hline Overall Total: & 47 men + & 51 women & 98 respondents \\
\hline
\end{tabular}

Biographical information about people Elizabeth Roberts interviewed in the late 1970s and early 1980s appears in the Appendix of her book, A Woman's Place: An Oral History of Working-Class Women 1890-1940 (Blackwell, 1984), 207-213. Transcripts of all interviews quoted in this paper are housed in the archives of the Center for North West Regional Studies, Lancaster University (Great Britain).

Roberts and I used an extensive interview instrument containing 237 questions, many of which were used twice - once for the interviewee's childhood and again for the interviewee's adult family experience. Use of the interview instrument was intended to provide comparative data for all interviewees. However, it was not a straight jacket. Interviews were semi-structured, with the interviewee exerting a 
good deal of control over the direction of interviews. Thus, interviewees often digressed from question topics; much useful information about health, ill-health, and both formal and informal management of what might be called "health incidents" (illness, injury, childbirth, and death) was volunteered by interviewees, not elicited by direct questions. The interview instrument included the following questions associated with these matters:

\section{Health, illness, medicine and death}

187. Back to your own childhood: would you describe yourself as having been a healthy or a sickly child?

188. Did you have any serious illnesses or injuries when you were a child? Describe.

189. Was anyone in your household ever seriously or chronically ill? Describe.

190. When someone in the household became ill, who made the decisions about what should be done?

191. When you were a child, did you and your brothers and sisters take anything to prevent illness (vitamins, tonics, laxatives, enemas, etc.)? Wear special clothing to prevent illness?

192. Did you or other family members go to the doctor very often? Did the doctor ever make house calls?

193. Was the doctor's advice always taken? (If not, why not?)

194. Who decided when it was necessary to consult the doctor?

195. Were doctor bills ever a financial burden in your family? What kind(s) of medical insurance have you had?

196. Did you or other family members ever obtain medical treatment or advice from practitioners other than doctors?

197. Did your family use any home remedies? (If so) Describe.

198. When you or other family members were ill, did you stay in bed? Eat special foods?

199. Were people in the house treated differently or specially when they were ill?

200. Concerning childbirth: were you born at home or in the hospital? Do you know who delivered you? Who was present at the birth?

201. Where were your own children born? Who delivered them? Who was present at the birth?

202. Where were your grandchildren born? Who delivered them? Who was present at the birth?

203. Did your mother have any childbirth preparation education before you were born? Did you?

204. Comparing experiences, did you/your wife or your mother have an easier time with childbirth? 
205. How long did your mother stay in bed after you were born? How long did you stay in bed after your children were born?

206. Did your mother/you have any help (from relatives, hired nurses, etc.) after a baby was born?

207. What kind of postnatal care did your mother/you/wife receive?

208. Did your mother/you take babies to the doctor on a regular basis?

209. Did your mother breastfeed her babies? Why/why not? How long?

210. Did you/your wife breastfeed your children? Why/why not? How long?

211. If babies were bottle-fed, were any special precautions taken about the bottles?

212. When did the babies begin to have solid food (i.e., how old were they?)

213. Did you/your mother/your wife go back to work after having children? How soon after delivery?

214. Were you immunized as a child? (DPT, polio, smallpox)

215. Were your own children immunized?

216. Did any of your children ever have any serious health problems?

217. Who made the decisions in your adult household about what should be done when someone became ill?

218. Did you go to the dentist regularly as a child? Did your own children go to the dentist regularly?

219. When you were a child, did anyone close to you die?

220. Where? (Hospital, home, other)

221. Did you visit him/her during the final illness?

222. Was she/he taken to a funeral home?

223. Did you go to the funeral/memorial service? If not, why not?

224. Can you describe the funeral and any gathering after the funeral was over?

225. Do you know whether he/she believed in a life after death? How about you (then and now)?

226. Did you lose any close relatives or friends up to 1970 ?

227. Have you ever looked after a dying relative in your own home?

228. Can you describe the funeral, and any gathering after the funeral was over?

229. Did he/she make any special requests about the funeral? About cremation or burial?

230. Did she/he make a will?

Lucinda McCray Beier, Ph.D., Department of History, Illinois State University 